\title{
Culture specific words as a barrier in cross- cultural communication in construction business
}

\author{
Tatiana Ivanova* \\ Moscow State Pedagogical University, Institute of Foreign Languages, 119991, Moscow, Malaya \\ Pirogovskaya St., 1, Bld. 1, Russia
}

\begin{abstract}
This research is an examination of the word as a cultural unit in cross-cultural communication in construction business. The qualitative analysis of some vocabulary units shows that simple words should be perceived as culture specific and might serve as barriers in cross-cultural communication. It is explained by the fact that speakers of different cultural backgrounds have little awareness about cultural associations that the word entails apart from its direct meaning. The comparative cultural research employed in the process of the study demonstrates that the perception of words largely depends on the type of culture the speakers represent, as well as the peculiarities of cultural, historical and social background of the latter. The results of the study are presented in the form of analysis of the linguistic data and cultural phenomena, which take place in cross-cultural communication.
\end{abstract}

\section{Introduction}

There is no need to highlight the fact that overcoming cultural barriers has become fundamental for doing cross-cultural business. It is especially relevant for Russia, where cross-cultural communication in business rocketed in 1991 and has been rising gradually ever since. For instance, the amount of foreign companies in the construction business in Russia is estimated to be holding around $15 \%$ of the market share [1], which includes Finnish, Turkish, British, French, Chinese and other developers. Consequently, there should be found ways to soothe cultural differences and accommodate the working environment for the needs of everyone. That is why it is only natural that there is a common challenge to raise cultural awareness globally, to cultivate tolerance and respect to cultural differences.

In this study, we will speak about possible problems in cross-cultural communication with allowance for the fact that, first, the business is conducted in Russia; second, for some communicators English and Russian are foreign languages. In addition to that, many examples provided would be concerning construction industry. Other examples which do not concern this field directly might still be applied to construction industry, since they are universal and are relevant to doing cross-cultural business in general.

\footnotetext{
${ }^{*}$ Corresponding author: redactora@yandex.ru
} 
The aim of the study is to examine the word as a cultural unit, which might serve as an obstacle in cross-cultural communication. The central idea of the article is that communicators in cross-cultural environment might often show unintentional disregard of culture-specific elements and facts of life in the country where they are conducting business. Together, that leads to misunderstanding and cross-cultural communication breakdown. By using the term unintentional, we emphasize the idea that this might happen even to communicators with a relative awareness of the target culture and cultural experience. The reason for that is rooted in the fact that communicators often pay more attention to culture-specific items, which have zero equivalents in their own culture, and to the words which are denoted by them respectively. However, even simple words used every day conversation might pose a certain cultural 'threat' to communicators with a different cultural background.

\section{Methods}

In this section, we will employ a comparative cultural research and a qualitative analysis of a range of vocabulary units in relation to the Russian culture and the cultures of English speaking cultures. It should be noted that all the generalizations, which will be made, should be perceived critically with allowance for exceptions, as each person has a unique worldview and experience, no matter the background and/or citizenship. The classification of vocabulary units presented further is based upon the studies of Newmark, Ter-Minasova and Wierzbicka. The cultural dimensions developed by Hofstede and Trompenaars are employed to show the differences between Russians and native English speakers.

\subsection{Defining the notion of culture specific vocabulary}

There have been various attempts at defining the notion of culture specific vocabulary. The term itself has a numerous number of synonyms, which makes it clear that such vocabulary has long been a popular subject of investigation for scholars engaged in the studies of linguistics, culture and other related fields. For instance, $O$. Chahrour describes a term or a word as 'culture specific' when it denotes a phenomenon (such as a piece of clothes, a belief, a social habit, etc.) typical of the studied/source culture. [2] M. Baker speaks about 'culture specific concepts' as items, which are common in the studied culture while being alien in other cultures/languages. [3] P. Newmark used a broader term, 'cultural words' referring to culturally specific features, also categorizing such words into groups. [4]

\subsection{Non-equivalents vs. equivalents}

Language insufficiency can manifest itself differently. It is evident, however, that a lack of a word or an expression in a language can be explained by the absence of the target notion in the speaker's environment. Thus, words with no direct equivalents in other languages will be applied when the situation demands it. The material and abstract phenomena denoted with their help stand alone; they belong to a unique world and a unique language respectively. $P$. Newmark categorizes such words into the following groups: (1) ecology, which includes flora, fauna and other types of natural phenomena; (2) material culture (artefacts): foods, items of clothes, houses; (3) social culture: work and leisure; (4) organization, customs, activities, procedures, concepts; (5) gestures and habits. [4]

If necessary, speakers might borrow a word to denote something non-existent in their own culture. These notions are becoming widespread in other cultures and undoubtedly illustrate some phenomena more vividly than synonyms, which already exist in the 
language. [5] These borrowed words and phrases sound foreign to native speakers and therefore attract attention. As a result, they usually cause certain emotions, since they are associated with foreign cultures. Even those English native speakers who have no connections with Russia are familiar with such notions as vodka, balalaika and ushanka, while Russian native speakers are aware of what whiskey, ale and cowboys are. However, the proportion of complete non-equivalents in the vocabulary of any language is rather moderate. In the Russian language, it is estimated to be no higher than 6-7\% according to the research of Vereschagin and Kostomarov. As Ter-Minasova points out, they represent an ultimate example of language insufficiency. [6]

Non-equivalents are well-studied by linguists and culture experts due to their scarcity. Non-equivalents have become favored by language students and linguists, as these words and phrases represent the ultimate essence of the culture of the studied language and are easily memorized. By contrast, there are words and phrases, which do have equivalents in different languages. Still, little thought is given to the difference, with which a Russian native speaker and an English native speaker may perceive one and the same notion.

Any word may serve as an example of a certain linguistic reality. One of the words of this kind is red. Oxford English dictionary presents several definitions of this adjective: 1) (informal) having the color of blood or fire: a red car / sunset. The lights changed to read before I could get across. 2) (of the eyes) bloodshot (=with thin lines of blood in them) or surrounded by red or very pink skin: Her eyes were red from crying. 3) (of the face) bright red or pink, especially because you are angry, embarrassed or ashamed: He stammered something and went very red in the face. 4) (of hair or an animal's fur) reddish-brown in color: a red-haired girl; red deer / squirrels. 5) (informal) (sometimes disapproving, politics) having very left-wing political opinions. The same noun red would also describe a person with very left-wing political opinions and red wine apart from the red color. [7]

Although the same color exists in both Russian and English, a certain number of differences will be obvious if we consider a dictionary entry for the same word in Russian. These meanings are presented in Ozhegov's Definition Dictionary of the Russian language:

Red means: 1) the color of blood, wild strawberry, the color of a poppy flower; 2) it is related to a revolutionary activity, the Soviet Union and/or the Soviet government; 3) (poetic) refers to something beautiful, fair, or good. Thus, the name 'Red Square' was originally understood as a 'beautiful' square and had no relation to the red color. 4) Refers to valuable wood species or fish species. 5) (historism) a person who was a supporter of the Bolsheviks during the Russian Civil War, or someone related to the Red Army. [8]

As it can clearly be seen, the word red does have a direct equivalent in Russian. Still, it will be perceived and understood differently by the representatives of these two cultures. These differences will be manifested even more profoundly if one considers the set-phrases and collocations with this word. In English these would be the following: red-brick (e.g. of universities in Britain), to be in red, a red eye (about a flight), red herring, red tape, red in tooth and claw. In Russian, the expressions with red would include to return the favor (literal translation: the debt is red/beautiful with payment), a common theme (literal translation: a red line in a story), gorgeous sunshine (red sunshine), a beautiful maiden (a red maiden), the maximum price (literally, the red/best/beautiful price).

Thus, it can clearly be seen that a Russian word red has mostly ancient associations with beauty and historical associations with the Soviet Union, most of which are either neutral or neutral / positive. At the same time, the English word red has association with red politics, which might be relatively negative, and bureaucracy, which is almost always negative.

As it was stated earlier, many words which are not completely equivalent in different languages, may be borrowed from one language into another. A relevant example of this kind is a noun developer, which was borrowed from English into Russian. It is interesting 
to note that the Russian language has a similar word, builder, but in modern media discourse a loan word developer has become much more popular specifically in construction business. A Russian native word builder ('stroitel') denotes a person who is involved in construction and engineering in a narrow sense; it might also denote someone who creates something new and important for the humanity in a broad sense. In case of the latter, the word is seldom used due to its lofty stylistic connotation. It is likely that a foreign developer was borrowed into Russian and has become so widespread because of its foreign 'flavor', but also because of the fact that a developer is neutral and broad in its meaning. It reflects the modern reality much better, as it denotes both "a person and a company that buys land or buildings in order to build new houses, shops/stores, or to improve the old ones, and makes a profit from doing this". [7, 8] Likewise, development is connected with not only creating new buildings, but with growth, creation and production of something more advanced. A new word was apparently borrowed to express new realities, since a traditional builder can only build and construct things, while a developer is a designer and a creator of a better environment.

Apparently, Russian and English native speakers have developed different ideas concerning seemingly the same notions. One of these is cold Russian winters and relatively unpleasant falls and springs, when the temperature might drop to low levels. Central heating system is another construction term, which causes a lot of misinterpretations. It has many synonyms in English, but is usually expressed with one single term in Russian. It is central heating, which not just helps people survive the harsh climate, but also makes Russians' life quite comfortable. That is why every time when a foreigner initiates a small talk with their Russian partner, there is a moment of misunderstanding. The Russian has to assure their foreign colleague that although the winter here might be cold, it is not fatal. On the contrary, it can be even hot inside a Russian house in the winter, thanks to the heating system. Usually, it is followed by another amused pause in the conversation, since for a foreigner this explanation does not seem plausible: after all, it is common knowledge that Russian winters are unbearable. As a result, both partners feel uncomfortable, as for a foreigner it might be hard to believe the Russian's explanations; the Russian might feel confused that he/she has to explain the idea of a heating system every time the conversation touches upon the climate. What is more, the Russian would feel even irritated if someone doubted the fact that the Russian might be cold at all.

\subsection{Denotation, connotation, semantic primes}

Linguists have developed an idea that the meaning of each word consists of two components, the denotation and the connotation. The denotation is a direct meaning of the word; it is its essence. Without it, communication becomes impossible. The connotation, however, is the additional meaning, which sometimes is only implied and cannot easily be distinguished.

As it was just shown with the examples of red, developer and central heating system, it should be noted that communication between the representatives of different cultures happens because the denotational component of the said notions is the same in both languages. Both speakers get the idea of the red color, and of the developer as someone who is involved in construction business. It is also clear that the central heating system brings warmth. However, it is the connotational components that are different in the two languages. Thus, misunderstanding takes place.

A question might be put forward: are there any words which have zero connotation? It is only natural to look for the words that would be 'safe' for any cross-cultural communication. Apparently, there are some, which might fill this need. Unfortunately, they represent a very small amount of vocabulary. A distinguished Polish linguist Anna 
Wierzbicka calls them 'semantic primes' since their meaning is the simplest and cannot fall into parts [9]:

Table 1. Some examples of semantic primes by A. Wierzbicka

\begin{tabular}{|l|l|}
\hline $\begin{array}{l}\text { i me, you, someone, something thing, people, } \\
\text { body }\end{array}$ & substantives \\
\hline this, the same, other $\sim$ else & determiners \\
\hline one, two, much $\sim$ many, little $\sim$ few, some, all & quantifiers \\
\hline good, bad & evaluators \\
\hline big, small & descriptors \\
\hline think, know, want, don't want, feel, see, hear & mental predicates \\
\hline $\begin{array}{l}\text { where place, here, above, below, far, near, } \\
\text { side, inside }\end{array}$ & space \\
\hline not, maybe, can, because, if & logical concepts \\
\hline very, more & augmentor, intensifier \\
\hline like similarity & similarity \\
\hline
\end{tabular}

It becomes obvious that this vocabulary is absolutely not enough to have a simple conversation.

\subsection{Cultural dimensions of national characters}

It is a proven fact that language is a mirror of culture, that is why it would be relevant to compare and contrast some aspects of the Russian culture and Western (English-speaking) part of the world. There are various classifications that have been developed for this matter. One of the most relevant classifications of cultures, which would also present the necessary background for the linguistic differences, would be a cultural model of Dr. Geert Hofstede. [10]

Hofstede distinguishes several dimensions of culture: power/distance, individualism, masculinity, uncertainty/avoidance, long-term orientation, and indulgence/restraint. In reference to construction business, it seems most logical to examine two of these indexes, Power/Distance (PD) and Long-Term Orientation (LTO), as a great deal of relevant cultural examples can be provided. [10]

PD index expresses the attitude towards power and equality in the society. In cultures with low PD index, it is common to view people as equals. Everyone is involved in the decision-making process; team work is highly valued. An employee can approach their supervisor with a question, and it will not be considered as a violation of the company's hierarchy. Such countries as the USA and the UK have a relatively low PD index (40/100 points and 35/100 points respectively), which means that power is dispersed among the employees. For instance, in Kiewit, an American contractor engaged in mining, construction and welding industry, it is highlighted that the company is employee-owned. [11] Balfour Beatty, a UK-based multinational company engaged in infrastructure services, develops the idea of inclusive environment, where people's differences are embraced to the full. [12]

On the other hand, Russia might serve as an example of a country with a high PD index (93/100). It means that Russian companies have a stronger hierarchy, where decisionmaking is rather centralized. When it comes to business meetings and other interactions, it is important to acknowledge the leader's position. Status symbols are not avoided; the leader's authority is unquestioned. One case might serve a good example, when the order 'from above' was carried out in its literal meaning. The Saint-Petersburg to Moscow Railway was built by the order of Emperor Nicholas I. Nowadays, the railroad is a subdivision of the Russian Railways (RZD). The legend says that when the Emperor was 
discussing the railroad project with his subordinates, one of them asked him a question how exactly the Emperor visualized the railroad on the map. Apparently, Nicholas I had a certain sense of humor: he took a ruler and a pencil and drew a direct line between Moscow and Saint-Petersburg, but the pencil which he was holding bumped into the other hand that was holding the ruler, thus a small curve spoiled the strict line. The Emperor's subordinates, however, took this 'plan' seriously, so the railroad between the two cities was built just the way it was sketched. It goes without saying that this example might be perceived with some skepticism. Still, taking into account the distance between the top management and the employees in most Russian companies, it seems rather plausible to any Russian.

LTO index shows how much the society values the philosophy of long-term planning and prioritizing present/future over past. Russia is a country with a high LTO index, [10] which means that the future is prioritized. It can easily be illustrated with examples in construction activities. In Russia, there have been various grand projects undertaken by the government as investments into the future. The Baikal-Amur Mainline, a railway 3,819 km long, was named a 'Construction Project of the Century', as it took nearly 50 years to construct the main part of the route, since the construction process was hold in harsh climatic and geological conditions. The amount of money invested in the project by 1991 was roughly estimated as $30 \$$ billion, the investment still continues. [13]

The Crimean Bridge would serve as another yet more modern example. A $19 \mathrm{~km}$ long bridge, it connects the Kerch peninsula and the Taman Peninsula and it is considered to be the longest in Europe. Its costs are estimated as 228 billion rubles, yet the construction process is not finished. [14] Many other examples of this kind could be provided. The Cathedral of Christ the Savior in Moscow, Petrodvorets in Saint-Petersburg, even the Moscow Metro, the stations of which were decorated with such thoroughness, stand out as examples of long-term orientation. It is hardly a surprise that such projects have always been criticized for the immensity of financial investments and human efforts, as both human and financial resources might be used elsewhere for present-day needs.

In 1997, a book called 'Riding the Waves of Culture' was published, where another seven dimensions of culture were presented by management consultants $F$. Trompenaars and Ch. Hampden-Turner. [15] These specialists developed a similar yet different system to categorize cultures, which goes as follows: (1) universalism versus particularism; (2) individualism versus communitarianism; (3) specific versus diffuse; (4) neutral versus emotional; (5) achievement versus ascription; (6) sequential time versus synchronous time; (7) internal direction versus outer direction. All of these dimensions can be illustrated with bright examples from engineering and construction industry, but we shall dwell upon Point 3 (specific/diffuse), as it seems the most relevant one.

Russia is a classic example of a diffuse culture, which means that Russians do not tend to separate work from their personal life. Building good personal relationships should be a priority, while business objectives might be discussed later. This system has some advantages the way Russians see it. For example, if an employee/worker has started to perform more poorly because of some personal problems, the manager is expected to show understanding and compassion. It is not frowned upon if people in a company share very personal problems with each other and spend time together in a bar after work. In many cases it is not perceived as completely rude or incorrect if a manager calls their employee on weekend or gives some extra tasks, which it would be possible to carry out only in one's spare time. As for construction sites, it is not infrequent when immigrants are employed. Immigrant families often live close or even within such construction sites, which makes work inseparable from home.

The UK and the USA are examples of specific cultures. In these cultures, work and personal life tend to be separated. A person might be reprimanded for their performance by 
a boss, but it will not be taken too personally by the person. Also, in specific cultures, it is not considered professional when one finishes work very late regularly or brings work home, because the two spaces should be divided. What is more, people of specific cultures do not have a tendency to associate with each other on a deeper level than colleagues. Building personal relations is not viewed as essential, since the result at work can be achieved by diligence and motivation. There is even a slightly derogatory neologism 'frolleague' in English, which refers to someone who is more than a colleague but less than a friend.

It should be stressed, however, that any classification of cultures is a generalization, which should not be taken too strictly. Also, any classification does not presuppose the idea that a certain cultural type is 'bad' or 'poorly organized'. Classifications only show the differences that should be taken into account.

It goes without saying that the process of formation of a national culture and a national mentality is by all means extensive and complicated. However, there are certain factors, which have been proposed by various distinguished scholars. Although Herodotus might be considered the first who delved into the national psychology, it was a French philosopher Montesquieu that studied the climate in relation to a nation's psychology. Montesquieu sited such factors as the climate, religion, governmental principles, laws, the past as the ones which entail the development of certain national features. Montesquieu prioritized the physical factors (the climate, geographical position and landscape) over the social ones (law, customs, government system). [16]

It will be only logical to develop this idea and argue the following: Russia's climate and vast territories influenced the mentality; the mentality is closely related to the national culture; culture is inseparable from the language. Thus, almost each unit of the language exists in a culturally marked context. Consequently, Montesquieu's theories explain the pessimistic outer direction cultural worldview that many Russians still adhere to. They also explain the emotional, historical, and other connotations that representatives of different cultures would imply or ascribe to the same words and expressions.

\section{Results and discussion}

The qualitative analysis of various vocabulary units showed that there are extremely few examples of words, which speakers of different languages perceive the same way. These examples would include only the simplest concepts that cannot be divided into more parts, the so-called semantic primes. All the rest of the vocabulary should be considered as nonequivalent, even if one and the same word or phrase exists in different languages. Usually, the representatives of different cultures will have different associations with the notions expressed. Communication might suffer because the speakers will give little or no thought to these cultural associations that lie beneath the main (denotative) meaning.

Communicators should admit that they have a biased view of historical, social and political phenomena of their own country as well as the country where they are doing business due to the dimensions that shaped their mentality. Moreover, speakers with different cultural background might even ascribe their own connotations to even the simplest words. There is no 'safe' vocabulary that might be used as lingua franca between partners in cross-cultural communication. The principal cross-cultural difficulties for specialists doing business in a foreign environment would lie not in the insufficient language level, but in the lack of cultural awareness. 


\section{Conclusions}

The qualitative analysis of vocabulary units and the comparative cultural research in the sphere of business and construction industry show that cross-cultural studies will not cease to be relevant in the globalizing world. It was revealed that specialists who are involved in international business processes might underestimate the cultural discrepancy which dominates the mindset of native speakers of different cultural backgrounds. The study revealed that we perceive the same words differently presuming that our partners perceive them the same way.

On many occasions, these breakdowns can be avoided if communication partners accept the fact that they follow many rules of behavior only instinctively. With many companies going global, there is a tendency towards flattening cultural discrepancy. We often borrow foreign words that have no equivalents in our native language, because they bring us the sense of global belonging and express our thoughts more precisely. However, to cope with cross-cultural communication breakdowns in businesses, it is indispensable to raise awareness between cultures on all the levels of communication.

\section{References}

1. Foreign Investors in Russian Construction Market, On-line: : http://kapitalrus.ru/articles/article/inostrannye_investory_v_rossijskom_stroitelnom_rynke/

2. O. Chahrour. T.J. Cultural Problems in Translation. July (2018). On-line: https://translationjournal.net/July-2018/cultural-problems-in-translation.html

3. M. Baker. In Other Words: A Coursebook on Translation. London: Routledge (1992)

4. P. Newmark. A Textbook of Translation. London: Prentice Hall, 95 (1988)

5. S. G. Ter-Minasova. Language and Cross-Cultural Communication. Moskva: Slovo (2000)

6. E. M. Vereschagin, V. G. Kostomarov. Language and Culture. M., (1990)

7. S. Wehmeier, C. McIntosh. Oxford Advanced Learner's Dictionary. Oxford: OUP (2004)

8. S. I. Ozhegov. Definition Dictionary. On-line: https://slovarozhegova.ru/

9. Wierzbicka, Cl. Goddard. Words and Meanings: Lexical Semantics Across Domains, Languages, and Cultures. Oxford UP (2014)

10. G. Hofstede, On-line: https://www.hofstede-insights.com/

11. Kiewit Corporation, On-line: https://www.kiewit.com/careers/why-work-here/

12. Balfour Beatty pic, On-line: https://www.balfourbeatty.com/careers/why-balfour-beatty/

13. Baikal-Amur Mainline, On-line: http://eng.rzd.ru/statice/public/en?STRUCTURE_ID=88

14. The General Costs for the Crimean Bridge were estimated to be 228 billion rubles. Kommersant (08.07.2016) On-line: https://www.kommersant.ru/doc/3032528

15. F. Trompenaars, Ch. Hampden-Turner. Riding the Waves of Culture. (NB Publishing, London, 2nd Ed., 1997)

16. Ch. de Montesquieu. The Spirit of the Laws. RK (2018) 